TURIZAM

Volume 16 , Issue 2

50-64 (2012)

\title{
The Role of Travel Intermediaries in the Development of Sustainable Mountain Tourism - the Case of Turkey
}

Icoz Onur*, Icoz Orhan**

Received: January 2012 | Accepted: May 2012

\begin{abstract}
The aim of the study is to investigate the current situation of mountain tourism and its sustainability in Turkey. Not only the tourism policies of the government are enough to promote a new alternative tourism type, but also the role and effects of tourism middlemen such as travel agencies, tour operators, and tour wholesalers cannot be denied in the promotion of a destination. Mountain tourism could be one of the best alternative tourism opportunities for many destinations if they have sufficient resources, namely naturally attractive mountains and related infra and/or superstructure.

Turkey and Aegean region have many attractive resources in this sense. In this research, in addition to analyzing the current situation in Turkey; ways of developing mountain tourism in a sustainable way as well as possible roles and effects of travel intermediaries in this area are questioned. With this purpose, the contents of the research vary differently. The first part depends on literature review presenting general definitions and discussions concerning mountain tourism. In the second part of the study, tourism policies in general and the mountain tourism policies of Turkish Government will be discussed. In the last part, the field survey is applied by developing and distributing questionnaire to major group A travel agencies in Turkey and outbound tour operators organizing tours to Turkey as well. The sample of the research consists of 83 firms and each was reached via e-mail. The data gained through the survey were analysed by computer based statistical program, SPSS 16. In the discussion part of the research, depending on the major findings, the comments and suggestions for further researches were developed.
\end{abstract}

Keywords: Sustainability, Mountain Tourism, Alternative Tourism, Tourism Product, Intermediary.

* Yasar University, Faculty of Economics and Business Administration, Department of Tourism Guidance and Travel Management, Selcuk Yasar Kampus, Bornova, 35160, Izmir/Turkey, Phone: +90 53245296 39, Fax: +90 2323745474 , e-mail: onur.icoz@yasar.edu.tr

** Corresponding author: Yasar University, Faculty of Economics and Business Administration, Department of Tourism Guidance and Travel Management, Selcuk Yasar Kampus, Bornova, 35160, Izmir/Turkey, Phone: +90 5324529639 , Fax: +90 23237454 74, e-mail: orhan.icoz@yasar.edu.tr 


\section{Introduction}

Turkey is one of the most popular emerging tourism destinations with respect to its natural beauty and cultural heritage. While $3 \mathrm{~S}$ has been assumed as one of the most important attractions in Mediterranean countries, the recent developments show that the tourists are seeking for different purposes and expectations nowadays. There is no doubt that the consumer preferences definitely shape the policies and programs of the countries to develop further attractions and new tourism products to survive in the rival. Hence mountain tourism can be considered as the newly developed and accelerated type of tourism in Turkey with the support of the Turkish Government.

The incoming tourists are generally interested in resorts and historical locations in Turkey. In addition the ingoing tourism movements are focusing on $3 S$, thermal and winter tourism consequently. With respect to the globalized expectations and needs of the consumers in 2Oth century, new and shining tourism type "mountain tourism" is getting familiar and popular. With regard to the geographical resources in Turkey, the incoming demand points out some important locations with the necessary natural foundation such as the mountains Ararat (Ağrl), Hakkari-Cilo \& Sat, Rize-Kaçkar, Kayseri-Erciyes \& Niğde-Aladağlar etc. Despite the fact that mountain tourism is getting familiar in Turkey as well, gaining advantage from this side of tourism mostly depends on the planned, settled developments targeting ingoing tourists. The most effective branch of mountain tourism is winter tourism and it is gaining importance day by day. National tourists used to relaxing in summer time, try to escape from the hard times of winter \& weather conditions, air pollution in the low season. That is why the new pursuit of relaxing in this part of the year emerged a new kind of tourism such as "winter tourism" and a new concept such as "Winter Sports". Especially the increase in number of mobilized people in Turkey, weekend holidays, and the increase in consumption power stimulates the participation in winter tourism beside summer tourism.

Since these issues stated above signify the importance of mountain tourism in Turkey, this research tries to enlighten the important aspects of this alternative tourism type. Further from this point, literature review concerning mountain tourism, some related definitions and the hidden and important sides are indicated. The efforts and policies of Turkish Government is analyzed in the following section and the last part of the research is consisting of the field research which is questioning the role of the intermediaries in the development process of this recently emerging alternative tourism type.

\section{Literature Review}

Mountain tourism has been a research area in tourism literature which is examined thoroughly addressing the economical \& natural advantages (Kruk et al, 2007; Snowdon, 2OOO), tourists' attitudes, perceptions and risks involved (Holden, 2003; Pomfret, 2006), and its link with sustainability (Kostopoulou, S., \& Kyritsis, I. , 2003; Perchlaner, 2005). Researchers agree that mountain tourism provides some opportunities and challenges in terms of employment, income, conservation of natural heritage whilst some threats such as the constraints on communication and mobility, isolation psychology, effects on environment and ecology (Banskota \& Sharma, I998; Geneletti \& Dawa, 2009; Godde et al, 2000; Kruk et al, 2007).

In many developing countries, tourism is widely accepted as a way to contibute to economic development, job opportunities and foreign revenues. Due to these factors tourism 
in the mountain regions worldwide has developed rapidly in the last decades (Geneletti \& Dawa, 2009). The advantages of mountain tourism and the live examples from different parts of the world encourage countries with adequate natural resources to find out the ways of conducting efforts aiming sustainability in this area (Perchlaner, 2005) because sustainability can be easily connected to almost all kinds and scales of tourism activities and environments (Clarke, 1997; Saarinen, 2006).On the other hand, mountain tourism in developing countries is also considered as a growing environmental concern because of its affect on seasonality, lack of suitable infrastructures and planning (Geneletti and Dawa, 2009).

Due to the mentioned importance of mountain tourism, researchers are interested in various aspects. Mostly researchers consider mountaineering as a popular form of adventure tourism (Beedie and Hudson, 2003; Pomfret, 2006). Buckley (2007) states that mountaineering and mountain biking are among the most popular activities of adventure tourism. Besides there is a potential risk in adventure tourism and the tourists seeking for adventure usually get face to face with some dangers which are too much involved in mountain tourism. For example; winter-sports are activities of mountain tourism such as skiing (Falk, 2008; Fredmen \& Heberlain, 2003; Lasanta et al, 2007; Needham \& Rollins, 2005 )and some risky cases included are "skiing accident," "getting lost on a ski tour", "cable car accident", "natural hazards (thunder, storm)".

The interests of the tourists who seek adventure are also analyzed through researches and the need plus interest in special adventurous events are questioned because adventure tourism is often described in terms of its motivation. Mountains, lakes, oceans, jungle, desert islands, and other wild places represent escape locations that offer excitement and potential adventure. This escape from the ordinary to the extraordinary provides a pleasurable experience that is central to tourism (Beedie and Hudson, 2003). Some traditional approaches describe the motivation of such sports in terms of risk and uncertainty seeking while sometimes because of thrill and exalted state they may encompass. This "risk theory" describes the inherent motive for these endeavours as being the challenge and danger posed by harsh or extreme natural circumstances (Gyimothy \& Mykletun, 2004). Trauer (2006) investigates the motives for special interests thoroughly and signifies the facts lying beneath the desire for risky activities such as mountain tourism. According to Trauer, the tourists may have some motives such as "increased importance of outdoor activities, awareness of ecological problems, educational advances, aesthetic judgement and improvement of self and society" therefore this self-improvement may aspire tourists to participate in adventure and sport activities. Tourists belonging the stated profile participate in activities such as mountain biking, mountaineering (scrambling, rope-work, travelling across glaciers, use of ice axes and crampons, acclimatisation and navigation), skiing, snowboarding, snowmobiling, snow shoeing, rock climbing, trekking, wildlife watching, backpacking and hunting (Pomfret, 2006). For example; backpackers are considered as the tourists fulfilling their feelings of risk, excitement and this kind of an experience has a profound impact on their lives (O'Reilly, 2006).

When the movements of the tourists worldwide are analyzed it is seen that increases in downhill skiing appear to have decreased in many places, while hiking, cross-country skiing, and snowmobiling increases (Fredman and Heberlein 2OOI). Skiing is seen as a potential alternative tourism type that may attract many tourists especially during the off-season in Mediterranean countries. Winter tourism and sports are the alternatives to extend seasonality therefore ski resort-based tourism development brings many economic benefits to a region as well as improvement of services and infrastructure (Lasanta et al, 2007). However, although skiing is getting very popular in many countries, climatic conditions and global 
warming is considered as one of the most important threats. Climate induced changes would probably have negative impacts but it cannot be possible to forecast the longer terms since there are still some uncertainties in climate change projections (Scott et al, 2007).

On the other hand the management of mountain areas must strive for a careful balance between the protection of natural resources, the needs of local people and the desires of tourists. Prime objective of any tourism strategy must be to protect the environment on which tourism depend. If tourism impact too much on the environment, visitors may degrade the very thing they are coming to enjoy. A sustainable approach must also embrace the social and economic effects of tourism ensuring that visitors enjoy their visit, local economy benefit, living standards are protected and the skills of local people are harnessed (Pechlaner, 2005)

\section{Mountain Tourism Policies of Turkish Ministry of Culture and Tourism}

Turkey has a rich geo-morphological and tectonic multi altitudinal structure which offers mountaineers attractive and interesting resources both for winter sports and trekking sort of activities. Many people visit these areas for mountaineering purposes each year (http:// www.kultur.gov.tr).

Turkish Ministry of Culture and Tourism defines I7 different types of tourism types, two of which are classified as mountaineering and winter tourism. Winter tourism is identified with skiing that is why it can be classified as part of mountain tourism as well. This classification draws attention to the most important tourism types in Turkey which are accepted as the sources of tourism revenues. Since Turkish Ministry of Culture and Tourism defines this tourism type with importance, it defines some important policies concerning mountain tourism (http://www.kultur.gov.tr).

First policy is about the legal regulations. In this frame, foreign tourists living outside Turkey should ask for permission in order to participate in mountaineering tourism. This permission procedure starts with the demand from the Turkish Ministry of Foreign Affairs through foreign representative offices. Foreigners living in Turkey should follow the same procedure if there exist a representative office and if not to the Turkish Ministry of Internal Affairs. In Turkey, the role of the intermediaries exists when the tourists apply to them and the travel agencies are obliged to transmit this application to the Turkish Ministry of Culture and Tourism. This application process should follow a deadline period. Accordingly, applications through foreign representatives outside the country should start two months in advance, and one month before if they live in Turkey. The visa applications should be well matched with their arrival objectives.

The important mountains which are convenient with mountaineering and so-called activities are classified as; Mounth Ararat (Ağrı) - Ağrı Dağı (5I65 m.), Antalya-Beydağlar (altitude 3069 m.), Kayseri-Mounth Erciyes (3916 m.), Mersin-Bolkar Mountains (the highest is 3524 m.), Niğde-Aladağlar (3756 m.), Rize-Kaçkar Range of Mountains (3932 m.), Tunceli-Mercan (Munzur) Mountains (337O m.) and Van-Mounth Süphan (4058 m.).

Apart from mountaineering, the most familiar tourism type is winter tourism and according to Turkish Ministry of Culture and Tourism, mountaineering is also included within this tourism type. Therefore most of the policies in this sense are linked to winter tourism.

With respect to winter tourism opportunities and skiing, the defined and labelled sites are seen below (http://www.kultur.gov.tr): 
I. Erciyes Winter Sports Tourism Center - KAYSERI

2. Palandöken Winter Sports Tourism Centers- ERZURUM

3. Sarıkamış Süphan Cıbıltepe Balıkdağ Çamurludağ Tourism Centers - KARS

4. Uludağ Winter Sports Tourism Center - BURSA

5. Ilgaz Winter Sports Tourism Center - KASTAMONU/ÇANKIRI

6. Davraz Winter Sports Tourism Center - ISPARTA

7. Köroğlu Dağı Tourism Area - BOLU

8. Hasandağı Winter Sports Tourism Centers- AKSARAY

9. Zigana Tourism Center - GÜMÜŞHANE

IO. Alanya Akdağ Winter Sports Tourism Center - ANTALYA

II. Kop Dağı Tourism Center - BAYBURT

I2. Ladik Akdağ Winter Sports Tourism Center - SAMSUN

I3. Ilgaz Kadınçayırı Yıldıztepe KTKGB - ÇANKIRI

I4. Çakırgöl Tourism Center - GÜMÜŞHANE

I5. Kartepe Tourism Center - KOCAELİ

I6. Alanya Akseki Tourism Center - ANTALYA

I7. Sapgör Winter Sports Tourism Center - BİTLİS

I8. Ergan Dağı KTKGB - ERZINCAN

19. Tarsus Gülek Karboğazı KTKGB - MERSİN

20. Fethiye Seki-Eren Dağı Winter Sports Tourism Centre - MUĞLA

These skiing sites which are available for winter sports (2O sites) are shown on figure I. This figure is a very well reflection of how Turkey has wealthy resources in terms of mountain tourism.

Ministry of Culture and Tourism announced “Turkey's Tourism Strategy 2O23” recently. According to this strategy there are important approaches concerning the development of tourism in Turkey. In this frame, there are some defined Tourism Development Regions, Tourism Corridors (hallways), Tourism Cities and Eco-Tourism Regions.

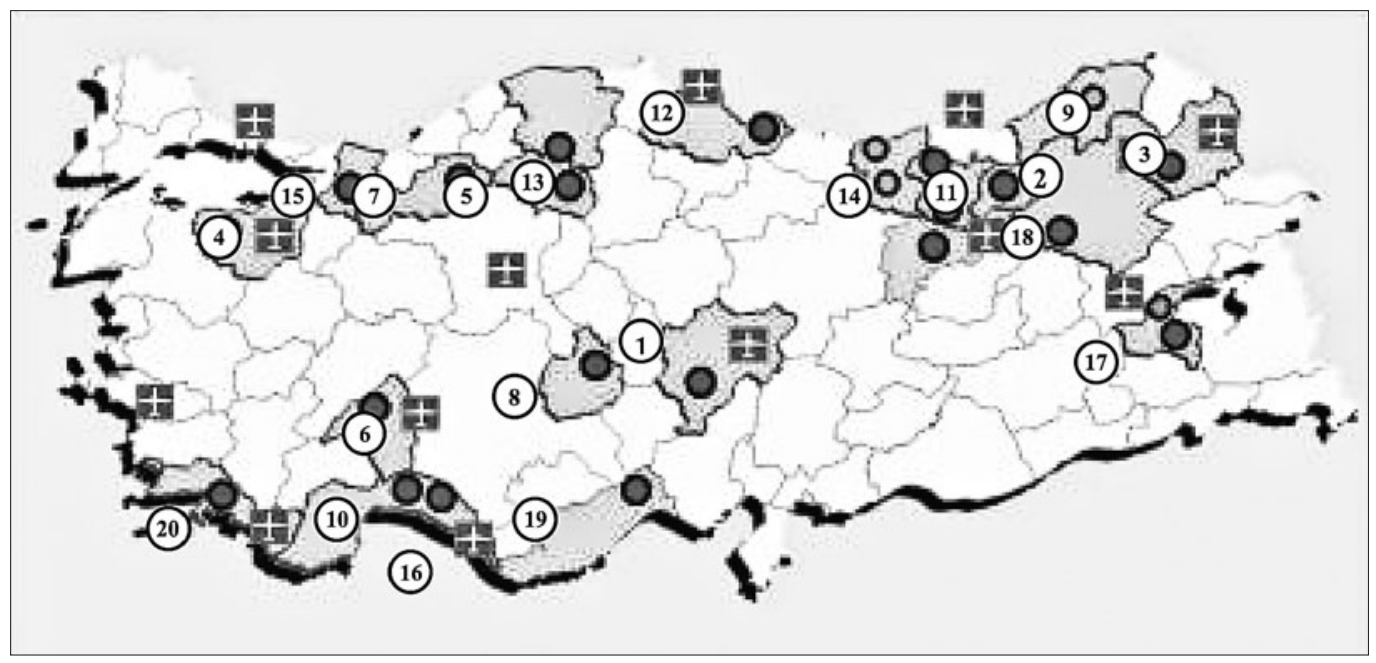

Figure 1. Winter Sports Sites

Source: Turkish Ministry of Culture and Tourism, http://www.kultur.gov.tr 
In the Strategy, the vision supports the sustainable development of tourism with respect to sustainable environmental policies. For the sustainability of tourism, it is indicated that the tourism products should be diversified and the seasonality factor should be eliminated by expanding tourism to I2 months. This seems possible with emerging different types of tourism such as congress, winter, and health tourism. In this frame, winter tourism is encouraged and accepted as a way of promoting tourism in low-season and maintaining sustainability. Accordingly, the strategy concerning winter tourism is determined as below (http://www.kultur.gov.tr):

- A detailed analysis is going to be made in order to find out the most appropriate areas for winter tourism

- The winter tourism regions will be handled in relation to thermal tourism, culture and congress tourism, mountaineering and eco-tourism.

- The planning efforts will be improved by the incentives and infrastructure practices of Turkish Ministry of Culture and Tourism

- In order to develop winter tourism, young generation will be leaded to sports activities

In addition, one of the tourism corridors in Strategy 2023 is identified as "Winter Corridor". In the light of "Winter Tourism Master Plan”, Erzincan, Erzurum, Ağrı, Kars and Ardahan are included as the most important cities with current potential resources to winter tourism. In these areas, new accommodation facilities are going to be developed and the quality will be improved. The stakeholders in this development process are considered as Turkish Ministry of Culture and Tourism, Local Government, Sectoral Establishments, Government Agencies and Turkey Skiing Federation.

\section{Research Objectives}

This study promotes three main objectives. First, it attempts to analyze the perceived image of mountain tourism of travel agencies in Turkey. Second, it examines and studies to determine the role of travel agencies' development efforts for mountain tourism in the country in terms of either inbound or domestic markets. Third, it aims to determine the general approach and perceptions of travel intermediaries about the public policies and strategies for developing mountain tourism in Turkey. Despite the growth of tourism industry, the interest towards it and the development of alternative tourism activities, few empirical studies approach the development of mountain tourism in Turkey.

The rest of the study is structured as follows; the methodology is described in advance, including specifications of the data collection, measures, and applied methodology. Then, the findings are illustrated, and finally, the conclusion and the consequent discussion indicate the utility of this research and note some limitations and future recommendations.

\section{Methodology - Data Collection}

In this study, the survey method is conducted and questionnaire technique is used to gather data from A Group Turkish Travel Agencies. The research was considered as exploratory research and the sampling method is probability random sampling. The universe of the research is totally identifiable and attainable via e-mail but since most of them haven't replied the questionnaire, only the respondents were considered as a sample. The total num- 
ber of the agencies (universe) is almost 4.600 in Turkey mostly located in a few largest cities of the country (Istanbul, Antalya, Izmir, Muğla etc.). The data was obtained from the official web page of the Association of Turkish Travel Agencies (TURSAB). More than 3,OOO e-mail addresses could be gathered from this web page and the web based questionnaire was sent to the agencies identified. 54I out of 3,OOO agencies could be reached via e-mail messages, between May - August 2009. And finally, 83 of these 54I agencies responded the questionnaire and sent them back to the e-mail address given to them beforehand.

The questionnaire consists of 32 questions which include two categories and three types of them were addressed to the respondents. The first category involves 8 questions and was designed to collect information about the demographics; profile of agency and general tourism services offered to their clients. This group of questions was considered as first group variables in order to cross tabulate the questions and for chi-square analyses. Second category involves mountain tourism related 24 questions which aim to measure the opinions of the respondent agencies about mountain tourism and they were considered as second group variables while analyzing cross tabulations of the responses. Most of the questions are multiple choice and respondents were generally supposed to mark more than one choice. For that reason, the total percentages are more than a hundred percent for most of the questions. The responses were analyzed by SPSS to test some hypotheses, which were formulated by the researchers.

\section{Measures and Data Analyses}

\section{Sample Profile}

According to the results, the distribution of the agencies observed are; 25 out of 83 agencies are located in Istanbul (3O,I \%) - the largest city-, followed by I4 in Antalya (I6,9 \%), and I2 in İzmir (I4,5 \%), IO (I2,O \%) in Muğla, 8 in Ankara (9,6 \%), 5 in Nevsehir (6,O \%), and the remaining in other small cities (II,9\%) respectively. The activity duration (as years) of the agencies are; $4 \mathrm{O}$ of them have been operating for more than $\mathrm{I} 3$ years $(48,2 \%)$, while I6 for less than 4 years (I9,3\%), II for 5 - 7 years (I3,3\%), 8 for 7-9 years (9,6 \%) and the remaining 8 for IO-I2 years $(9,6 \%)$. In summary, more than half of the agencies have been operating for more than IO years and therefore they are supposed to be relatively experienced travel intermediaries (Table I).

As for the employee profile, we know that agencies are mostly small and medium sized enterprises thus they employ fewer personnel than many other service operations. The results confirm this feature of the agencies. 45 of the agencies $(54,2 \%)$ employ less than 7 personnel, and only 22 of them (26,5\%) employ more than I5 staff. The number of personnel of the remaining (I8 \%) changes between 8 - I4.

With respect to the main services offered by the agencies; mostly domestic tours (78,3 \%), hotel reservations $(69,9 \%)$, followed by airline ticket sales $(65, \mathrm{I} \%)$, blue tours in Southern Anatolia and yachting (50,6\%), outbound (international) tours (50,6\%), meeting and congress organisations $(50,6 \%)$, car rentals (47,0 \%), cruising $(28,9 \%)$ and faith tours to Mecca (I6,9 \%) respectively.

As one of the very effective communication and marketing tool, internet connections and web page ownership are considered to be the most important tools for agency sales and promote their services to the potential buyers. Most of the agencies have their own web page 
Table 1. Location Distribution of Travel Agencies by Region

\begin{tabular}{|l|r|r|}
\hline Location & Number of Agencies & Relative Share (\%) \\
\hline İstanbul & 25 & 30,1 \\
\hline Antalya & 14 & 16,9 \\
\hline Izmir & 12 & 14,5 \\
\hline Muğla & 10 & 12,0 \\
\hline Ankara & 8 & 9,6 \\
\hline Nevsehir & 5 & 6,0 \\
\hline Others (small cities) & 9 & 11,9 \\
\hline Total & 83 & \\
\hline
\end{tabular}

Table 2. Services offered by Travel Agencies (more than one services)

\begin{tabular}{|l|r|r|}
\hline Type of Services & Number of Agencies & Relative Share (\%) \\
\hline Domestic tours & 65 & 78,3 \\
\hline Hotel reservations & 58 & 69,9 \\
\hline Airline Ticket sales & 54 & 65,1 \\
\hline Blue tours and yachting & 42 & 50,6 \\
\hline Outbound tours & 42 & 50,6 \\
\hline Meeting \& Congress & 42 & 50,6 \\
Organisations & 39 & 47,0 \\
\hline Car rentals & 24 & 28,9 \\
\hline Cruising & 14 & 16,9 \\
\hline Faith tours to Mecca & &
\end{tabular}

(75.9\%), but only a few of them (37,3\%) are connected to a CRS system to develop their sales and to offer better services to their clients.

The final profile question was concerning the categories of domestic tours if available. In this section, the leading tour categories are as the follows; historical and cultural tours $(80,7 \%)$ sightseeing tours $(\% 78,3)$, sports related tours $(48,2 \%)$, rural tours $(45,8 \%)$, health tours $(44,6 \%)$, golf tours (I3,3\%), meeting \& congress (25\%), special interest tours-like bird watching (I5 \%). As seen, mountain tourism could be categorised as a part of sports related tours like downhill skiing, trekking, climbing, and paragliding etc. according to the Travel Agencies participating the survey.

Table 3. Categories of Domestic Tours offered by Travel Agencies (more than one services)

\begin{tabular}{|l|r|r|}
\hline Type of Services & Number of Agencies & Relative Share (\%) \\
\hline Historical and cultural tours & 67 & 80,7 \\
\hline Sightseeing tours & 65 & 78,3 \\
\hline Sports related tours & 40 & 48,2 \\
\hline Rural tours & 38 & 45,8 \\
\hline Health tours & 37 & 44,6 \\
\hline Golf tours & 11 & 13,3 \\
\hline Meeting \& congress & 21 & 25,3 \\
\hline Special interest tours & 13 & 15,6 \\
\hline
\end{tabular}




\section{The Views of Travel Agencies Concerning Mountain Tourism}

In this part of the survey, responses for 24 questions are analysed. The frequency analysis indicate that, 44 of the agencies $(55,4 \%$ ) organised mountain tours at least once so far and only $27(32,5 \%)$ respondents indicated that they have employed a specialist guide for mountain tour. On the other hand, 6I (72,3\%) agencies responded that they would organize mountain tours if there were sufficient demand in the near future. These findings show that, most of the agencies in Turkey consider the mountain tourism as an alternative activity or product for their business objectives and they have a positive approach about mountain tourism.

Respondent agencies were asked concerning the relative share of mountain demand in their sales. II agencies explained that the relative share of mountain tourism demand is $30 \%$ or more in their total sales, while for 13 agencies the share is less than $5 \%$, for 6 agencies the share is 7- IO \%, for 4 agencies it is II - I5 \%, for 3 agencies I6 - 20 \% and for 3 agencies the share is $2 \mathrm{I}-29 \%$. The remaining 43 out of 83 agencies didn't give any response. This data shows that there is no serious demand share mountain tourism in total sales. For very small number of agencies, mountain tourism is still a negligible tourism activity.

For the demographics of the demand for mountain tourism, the data shows that most of the visitors are students (53\%), self employed (47\%), academicians (38,6 \%) and businessmen (36,I \%). Their income categories are upper-middle income $(63,9 \%)$, and their age categories are $3 \mathrm{I}-4 \mathrm{O}(57,8 \%), 26-3 \mathrm{O}(44,6 \%)$ and $\mathrm{I} 9-25$ (4I \%). The average group size is mostly IO to I5 $(95,2 \%)$ and rarely tours are organized with the groups more than 20 or more participants (I3 \%). Finally the most popular periods are concentrated on March through September. The distribution of the periods are, March-April (9,6 \%), May-June (I5,7\%), July-August (27,7 \%) and September-October(I4,5\%). There is a low demand for the periods of January-February $(8,4 \%)$ and November-December $(3,6 \%)$.

Agencies were questioned whether there was a sufficient supply for mountain tourism in Turkey in terms of infrastructure and superstructure. They marked positively the option "yes" at 50 \% response rate, 25,3 \% marked negatively as "no", and while I2 \% marked the "no idea" option. I2 \% of the agencies didn't respond.

The following question was about the types of activities which could be categorised or considered as mountain tourism. According to the responses, trekking marked as the highest percentage (90,4\%), the second is stating at mountain resorts and/or buildings (80,7 \%), mountain climbing is the third $(78,3)$, the next is winter skiing - mostly downhill $(66,3 \%)$, others are mountain sports including paragliding (57,8 \%), cavern tours (54,2\%), bird watching/ornithology $(44,6 \%)$, hunting $(43,4 \%)$, and rafting (4I \%) respectively.

Most popular and top three mountains for tourism in Turkey are; Kaçkar Mountains (66,I \%) in the Northern Anatolia, Mount Ararat in the Eastern Anatolia (59 \%) which is the second, and Erciyes Mountain in Central Anatolia as the third popular mountain. The other popular mountains are as follows; Aladağlar in Central Anatolia (39,8 \%), Bursa Uludağ in the Western part of Anatolia (39,8 \%), Ilgaz and Karadağ in Northern Region of the Country (38,6 \%).

The other question was about the complementary activities or tours for mountain tourism. The respondents stated that these tours include; Sport tours (63,9\%), Historical tours (60,2 $\%)$, Winter tours (55,4 \%), Eco-tours (55,4 \%), Cavern visits (47\%), Rural tours (45,8 \%) and Youth tours $(44,6 \%)$.

Two types of questions were designed to find out the basic advantages and disadvantages of mountain tourism. According to the results, the most important three advantages are, it's integrity with the nature and its sustainability (79,5 \%), its active and dynamic feature $(75,9$ $\%)$, and exploratory characteristic (7I,I \%). The other advantages are, its exciting feature $(66,3$ 
$\%)$, healthiness (66,3\%), goodness for physical development (65,I \%), environmental sensitiveness in nature $(55,4 \%)$, scenic attractiveness $(43,4 \%)$ and its novelty (3O,I \%).

With regard to disadvantages of mountain tourism, the most indicated disadvantages are; its requirement of special equipment (57,8\%), riskiness and dangerousness $(55,4 \%)$, and "it doesn't fit to each age categories" (54,2 \%). Other disadvantages are, requirement of physical power (47\%), sometimes harmful for the nature (if there is no attention) (44,6\%), its unsuitability for disabled people (39,8\%), relatively expensiveness (38,6\%), strenuousness (32,5\%) and heavy infrastructure and superstructure requirement for some types of mountain tourism like winter skiing (34,9\%).

According to the Respondent Agencies, the most popular and favourable regions for their foreign clients are; the Great Mount Ararat (47,O \%) (5,I57 mt altitude) - East, Kaçkar Mountains (39,8 \%) - Northeast (3,932 mt), Beydağlarl (26,5 \%) - South (3,086 mt), Mounth Erciyas (24,I \%) - Centre (3,9I7 mt), Suphan - Nemrut (I9,3\%) - South East (4,058 mt), Bursa Uludag (I5,7 \%) - West (2,543 mt), Bolkar Mountains (I3,3 \%) - Center (3,254 mt.), Ilgaz and Mountblack (Karadag) (9,6 \%) - Northwest (2,587 mt), Mount Hasan (7,2 \%) - Centre (3,278 mt) .

The other question aimed to investigate the likely reasons for insufficient internal (domestic) demand for mountain tourism in Turkey. The highest possible reason was indicates as insufficient promotion, marketing efforts and lack of information about mountain tourism resources at 8I,9 \% response rate. The second reason was the lack of specialist guide for mountain tours (at $54,2 \%$ rate), the third reason was indicated as the underdevelopment of mountain tourism in Turkey (48,2 \%). Other reasons are, insufficient number of agencies specialized for mountain tours $(39,8 \%)$, the requirement of special equipment for mountain tours $(38,6 \%)$, lack of sufficient interest for mountain tours (32,5\%), insufficient income level of the potential domestic visitors $(25,3 \%)$, its somewhat riskiness (24,I \%), it's recognition as an activity for young individuals (24,I \%), not finding any harmonious group (2I,7 \%), it's relatively expensiveness.

The final three questions addressed to the respondents were about the thoughts of the agencies for the policies implemented by Ministry of Tourism and Culture. The first question was about whether the ministry had effective policies for developing mountain tourism in Turkey or not. The option "yes" was marked as I4,5\%, while "no" is as $5 \mathrm{I} .8 \%$ and "no idea" is as $33,7 \%$. Second question aimed to investigate whether the policies of the ministry for developing mountain tourism were sufficient or not. The responses as yes: 2,4 \%, no $69,9 \%$ and no idea: $27,7 \%$. Final question was about if there were any bureaucratic barriers and obstacles for organizing a mountain tour in Turkey or not. The results were consequently; yes: $53,3 \%$, no: $15,7 \%$ and no idea: $3 \mathrm{I} .3 \%$ response rate.

These three results explain us the agencies are complaining the lack of interest of the ministry for mountain tourism and there are considerable amount of obstacles to organize a mountain tour.

\section{Cross-tabulations and Chi-Square Analyses}

In this part of the study, meaningful associations between the variables are analyzed especially between independent profile variables and dependent variables signifying agencies' thoughts about mountain tourism.. Each independent variable was considered as potentially in relation to the dependent variables and then there could be some associations among some of the independently variables themselves. These associations were devised as hypothesis tests at the same time. For this purpose, almost 30 associations were considered most likely meaningful and they were included into chi-square analysis procedure by using statisti- 
cal package program (SPSS I3.O). According to the results of the analyses, only 9 statistically meaningful associations were found. The hypothesis tests and the results of chi-square analyses are as follows where the Hypotheses were stated in the null and alternate;

\section{Analysis - 1}

$\mathrm{HI}_{\mathrm{O}}$ : There is no association between the location of the agencies and the service categories they offer.

$\mathrm{HI}_{\mathrm{I}}$ : There is an association between the location of the agencies and the service categories they offer.

Pearson Chi Square: 938,023

$\mathrm{p}=, \mathrm{OOO}$

Likelihood ratio: 768,625

Ho: rejected and so there is an association between these two variables.

\section{Analysis - 2}

$\mathrm{H} 2_{\mathrm{O}}$ : There is no association between the location of the agencies and the agency thoughts about the bureaucratic barriers (obstacles) imposed by government for organizing a mountain tour.

$\mathrm{H} 2_{\mathrm{I}}$ : There is an association between the location of the agencies and the agency thoughts about the bureaucratic barriers (obstacles) imposed by government for organizing a mountain tour.

Pearson Chi Square: 28,030

$\mathrm{p}=$,O3I

Likelihood ratio: 29,293

Ho: rejected and so there is an association between these two variables.

\section{Analysis - 3}

$\mathrm{H}_{3}$ : There is no association between the agencies that have organized a mountain tour so far and the relative share of mountain tourism demand of the agency sales.

$\mathrm{H}_{3}$ : There is an association between the agencies that have organized a mountain tour so far and the relative share of mountain tourism demand of the agency sales.

Pearson Chi Square: I6,654

$\mathrm{p}=$,OII

Likelihood ratio: 19,293

Ho: rejected and there is an association between these two variables.

\section{Analysis - 4}

$\mathrm{H}_{4}$ : There is no association between the agencies that have organized a mountain tour so far and the agencies that employ a specialist guide for mountain tours.

$\mathrm{H}_{4}$ : There is an association between the agencies that have organized a mountain tour so far and the agencies that employ a specialist guide for mountain tours.

Pearson Chi Square: 34,905

$\mathrm{p}=$, OOO

Likelihood ratio: 4O,24I

Ho: rejected and so there is an association between these two variables. 


\section{Analysis - 5}

$\mathrm{H}_{5}$ : There is no association between the agencies that have organized a mountain tour so far and the agency's thoughts about the seasons for organizing mountain tours.

$\mathrm{H}_{5}$ : There is an association between the agencies that have organized a mountain tour so far and the agency's thoughts about the seasons for organizing mountain tours.

Pearson Chi Square: I7,802

$\mathrm{p}=, \mathrm{OO} 7$

Likelihood ratio: 19,063

Ho: rejected so there is an association between these two variables.

\section{Analysis - 6}

$\mathrm{H6}_{\mathrm{O}}$ : There is no association between the agencies that have organized a mountain tour so far and agency's thoughts whether there is a sufficient demand for mountain tours in Turkey or not.

H6 $6_{\mathrm{I}}$ : There is an association between the agencies that have organized a mountain tour so far and the agency's thoughts whether there is a sufficient demand for mountain tours in Turkey or not.

Pearson Chi Square: I5,733

$\mathrm{p}=, \mathrm{OO} 7$

Likelihood ratio: 19,567

Ho: rejected so there is an association between these two variables.

\section{Analysis - 7}

$\mathrm{H}_{7}$ : There is no association between the agencies that have organized a mountain tour so far and agency's thoughts about the mountain tourism policies implemented by Tourism Ministry in Turkey.

$\mathrm{H}_{7}$ : There is an association between the agencies that have organized a mountain tour so far and agency's thoughts about the mountain tourism policies implemented by Tourism Ministry in Turkey.

Pearson Chi Square: I5,496

$\mathrm{p}=, \mathrm{OOO}$

Likelihood ratio: $\mathrm{I} 6,932$

Ho: rejected so there is an association between these two variables.

\section{Analysis - 8}

$\mathrm{H}_{\mathrm{O}}$ : There is no association between the agencies that would like to organize a mountain tour if sufficient demand is available and the agency's thoughts whether there is a sufficient demand for mountain tours in Turkey.

$\mathrm{H} 8_{\mathrm{I}}$ : There is an association between the agencies that would like to organize a mountain tour if sufficient demand is available and the agency's thoughts whether there is a sufficient demand for mountain tours in Turkey.

Pearson Chi Square: I5,082

$\mathrm{p}=, \mathrm{O} 5 \mathrm{O}$

Likelihood ratio: 16,943

Ho: rejected so there is an association between these two variables. 


\section{Analysis - 9}

$\mathrm{H}_{9}$ : There is no association between the agencies that would like to organize a mountain tour if sufficient demand is available and the agency's thoughts about the bureaucratic obstacles imposed by government for organizing a mountain tour.

$\mathrm{H9}_{\mathrm{I}}$ : There is an association between the agencies that would like to organize a mountain tour if sufficient demand is available and the agency's thoughts about the bureaucratic obstacles imposed by government for organizing a mountain tour.

Pearson Chi Square: I4,I29

$\mathrm{p}=, \mathrm{O} 28$

Likelihood ratio: $\mathrm{I} 4,4 \mathrm{I} 7$

Ho: rejected so there is an association between these two variables.

\section{Conclusion}

Traditional $3 \mathrm{~S}$ and culture or sightseeing oriented tourism have been the most popular types of tourism all over the world and especially in a country full of geographical beauties and a natural heritage such as Turkey. With a quick glance at the tourism figures and statistics issued by WTO and/or government bodies, it is apparent that the very high percentage of tourists visiting tourism destinations participates in so called activities as indicated above. In other words, leisure tourism demand depends heavily on the purposes of resting, actively or passively participating in sport activities, sunbathing, swimming, shopping and relaxing. All these destinations are generally open to mass tourism that is why more and number of visitors generally create many environmental problems either on the natural or social environment.

Many destinations and governments (local or central) that realised the increasing potential of those kinds of problems have already started to develop new tourism types which are especially sensitive to the environment. The most popular and developing new types of tourism might be mountain based tourism such as skiing, climbing, paragliding, mountaineering, hiking and trekking, where these activities are addressed only as a small and specific part of total tourism demand in many destinations.

Most of the above mentioned activities cannot be participated without any specialist intermediary such as a travel agency or a tour operator. In this study, the conditions of the mountain tourism and the policies imposed by government are enlightened where the role and functions of the intermediaries for developing mountain tourism in Turkey was also questioned depending on the data gathered from leading travel agencies in Turkey.

According to the data, there are some mountain based tours in the country organised by the agencies, but they are at insufficient level in terms of the number of participants and expenditures for this activities. Only the limited number of agencies is organizing mountain based tours, but most of the firms are volunteer to take part of this alternative tourism option. Considerable amount of the agencies pointed out that there is no effective mountain tourism policy and so the necessary regulation imposed and implemented by the official authorities, while the country has noteworthy resources and attractiveness for mountain tours. Respondents also pointed out that mountain tourism could be complementary tourism activity for many other types of tourism such as sport tours, historical tours, winter tours, eco tours, cavern tours, rural tours etc. Despite some of the disadvantages of mountain tours, the firms agree that mountain tourism is a significant alternative to sustain the development of tourism in the country. 
This study aims to give some general information about the mountain tourism in Turkey and the roles of intermediaries. It is not an in depth analysis of demand side or supply side of this specific kind of tourism. It also aims to open a door for the further research about mostly demand side analyses of mountain tourism.

\section{References}

Banskota, K. \& Sharma, B. (I998). Mountain Tourism for Local Development: Training Manual for Local Community Groups and Organisations. Nepal: International Centre for Integrated Mountain Development and Centre for Resource and Environmental Studies.

Beedie, P. \& Hudson, S. (2003). Emergence of Mountain-Based Adventure Tourism. Annals of Tourism Research 30 (3),625-643.

Buckley, R. (2007). Adventure Tourism Products: Price, Duration, Size, Skill, Remoteness. Tourism Management 28, I428-I433

Falk, M. (2008). A Hedonic Price Model for Ski Lift Tickets. Tourism Management 29, II72- II84.

Fredmen, P. \& Heberlain, T.A. (2003). Changes in Skiing and Snowmobiling in Swedish Mountains. Annals of Tourism Research 30 (2), 485-488.

Geneletti, D. \& Dawa, D. (2009). Environmental Impact Assessment of Mountain Tourism In Developing Regions: A Study In Ladakh, Indian Himalaya. Environmental Impact Assessment Review 29, 229-242.

Godde, P.M., Price, M.F. \& Zimmermann, F.M.(2OOO). Tourism and Development in Mountain Regions. Oxon: CABI Publishing.

Gyimothy, S. \& Mykletun, R.J. (2004). Play in Adventure Tourism: The Case of Arctic Trekking. Annals of Tourism Research 3I (4), 855-878.

Holden, A. (2003). Investigating Trekkers' Attitudes to the Environment of Annapurna, Nepal. Tourism Management 24, 34I-344.

Kostopoulou, S., \& Kyritsis, I. (2003). Local People's Perceptions of Sustainable Tourism Development in Protected Mountain Areas: The Case of Mount Olympus, Greece. Sustainable World 6, 47-58.

Kruk, E., Hummel, J. \& Banskota, K. (2007). Facilitating Sustainable Mountain Tourism: Volume 2-Toolkit. International Centre for Integrated Mountain Development, SNV Netherlands Development Organisation, Nepal Tourism Board, Nepal: International Centre for Integrated Mountain Development.

Lasanta, T., Laguna, M.\& Vicente-Serrano, S.M. (2007). Do Tourism-Based Ski Resorts Contribute to the Homogeneous Development of the Mediterranean Mountains? A Case Study in the Central Spanish Pyrenees. Tourism Management 28, I326-I339.

Needham, M.D., \& Rollins, R.D. (2005). Interest Group Standards for Recreation and Tourism Impacts at Ski Areas in the Summer. Tourism Management 26, I-I3.

O'Reilly, C.C. (2006). From Drifter to Gap Year Tourist Mainstreaming Backpacker Travel”. Annals of Tourism Research 33 (4), 998-IOI7.

Perchlaner, H. (2005). Sustainable Tourism in Alpine Regions. EURAC research - European Academy Bozen-Bolzano.

Pomfret, G. (2006). Mountaineering Adventure Tourists: a Conceptual Framework for Research. Tourism Management 27, II3-II9. 
Scott, D., Jones, B. \& Konopek, J. (2007). Implications of Climate and Environmental Change for Nature-Based Tourism in the Canadian Rocky Mountains: A Case Study of Waterton Lakes National Park. Tourism Management 28, 57O-579.

Snowdon, P., Slee, B., Farr, H., \& Godde, P. M. (2OOO). The economic impacts of different types of tourism in upland and mountain areas of Europa. In P. M. Godde, M. P. Price \& F. M. Zimmermann (Eds.), Tourism and Development in Mountain Regions (I37-I45). Wallingford: CAB International.

Trauer, B. (2006). Conceptualizing Special Interest Tourism - Frameworks for Analysis", Tourism Management 27, I83-200.

Turkish Ministry of Culture and Tourism, http://www.kultur.gov.tr (O5.IO.2OII) 